Research Article

Available at http://inpressco.com/category/ijcet

\title{
Determination of the Solidification Time of Al-7\%Si Alloy during Centrifugal Casting
}

\author{
P.Shaliesh $\dot{\mathrm{A}}^{*}$, B. Praveen Kumar ${ }^{\dot{\mathrm{A}}}, \mathrm{K}$ Vijaya Kumarc ${ }^{\mathrm{c}}$ and A Nagendra ${ }^{\dot{\mathrm{A}}}$ \\ ${ }^{\AA}$ St. Peters Engineering College,Kompally, Hyderabad, A.P, India. \\ ${ }_{\dot{B}}^{\dot{B}}$ National Institute of Technology Warangal, A.P, India.
}

Accepted 10 January 2014, Available online 01 February 2014, Special Issue-2, (February 2014)

\begin{abstract}
The present work deals with an experimental and a theoretical investigation to determine the solidification time of cast components produced by centrifugal casting methods with different speeds. Al-7\% Si alloy is considered in the present investigation at different pouring temperatures and rotational speeds. Solidification times are measured and a suitable mathematical formulation to estimate the freezing time is proposed. In the present work a horizontal axis centrifugal casting is studied both experimentally and numerically. Polar coordinate system is considered during the analysis and numerical investigation. Temperature dependent properties of aluminium alloy are taken into consideration for estimation of the solidification time. Radiative heat transfer from the outer surface of rotating cast iron mould is also taken into account along with convective heat transfer. The results are presented in both tabular and graphical from and comparisons made.
\end{abstract}

Keywords: Al-Si Alloy, Centrifugal Casting, Solidification Time.

\section{Introduction}

Centrifugal casting is extensively used for many applications of components made out of Aluminum alloys. The products made by centrifugal casting have better integrity than the components made by permanent mould Casting Process. A casting machine rotates the mould about a horizontal axis. Al-Si alloy at about $720^{\circ} \mathrm{C}$ and $780^{\circ} \mathrm{C}$ is fed into the mould through a pouring spout. As the liquid Al-Si alloy comes into contact with the mould it is spread centrifugally over the surface and then freezes. During this time heat is conducted between the outside surface of the mould and hot Al-Si alloy as shown in pro E-model and linear diagram in fig 1 and fig 2.

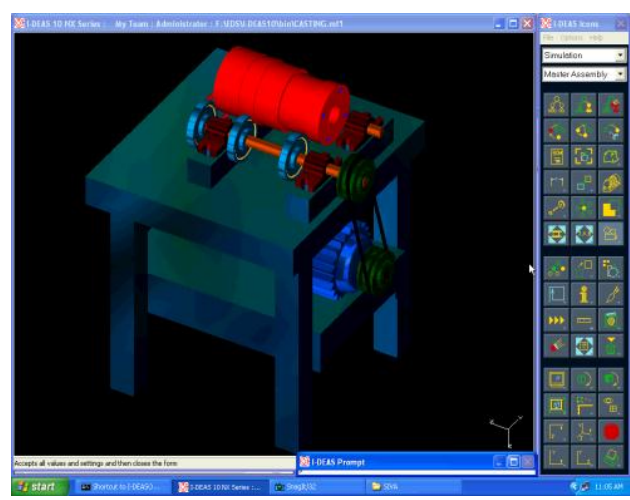

Fig 1: Horizontal Centrifugal Casting Pro-E Model

*Corresponding author: P.Shaliesh

DOI: http://dx.doi.org/10.14741/ijcet/spl.2.2014.40
The internal surfaces of the metal moulds used in horizontal centrifugal casting are usually coated with a thin layer of insulating material before they come in contact with poured liquid metal. In this study analysis was made on Al-Si (4450 of IS 617:1975) for the radial temperature distribution with in the mould and molten method are utilized in estimating the solidification time. The solidification time behavior of a tubular part for centrifugal casting is influenced by various parameters like nature of the alloy, shape and size of the casting and thermo-physical properties of metal and mould. (Roshan et.al 1974), (Bahadoriet.al 1971)

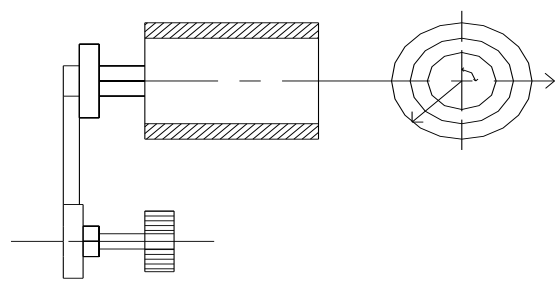

Fig: 2Graphical diagram Horizontal Centrifugal Casting

The numerical simulation of this process is challenging, no description of its numerical simulation was found in literature. Some papers describe the less complex vertical centrifugal casting process (Kaschinitz et.al, 2012).

Though an exhaustive literature survey it is understood that very little work was carried on the estimating of freezing time on centrifugal casting of Aluminum alloys. There are several theoretical and experimental 
investigations that involve the determination of the solidification time of aluminum alloys in casting area. Some of the important contributions in this area have been presented here to give the current state of ar (Jezierski.J et.al 1970) (Lazardis.A et al1970).

A numerical solution is obtained for the solidification of a steel casting in a thermally insulated mould. The effect of the rate of metal pouring on the motion of the solidification interface is investigated. An experimental and numerical model on the time varying heat transfer coefficient $\mathrm{h}(\mathrm{t})$ between a tube-shaped casting and metal moulds. One-dimensional treatment was adopted in analyzing the heat flows between the casting and the inner and the outer mould (Tae-Gyu Kim et.al 1997) (Minosyan Ya P et.al 1983)

\section{Experimental Investigations}

A mathematical model for a Horizontal Centrifugal Casting for 4450 (Al-6.5-7.5\% Si) alloy has been developed using a polar co-ordinate system. The average properties of the material are taken in the appropriate temperature range. Specific heat, density and thermal conductivity values are averaged for solid and molten metals. The radial temperature distribution with in the mould and molten metal are utilized in estimating the freezing time. In the estimation of heat transfer conduction in polar coordinate system, average values of air temperature are assumed to be about $35^{\circ} \mathrm{C}$ which represents a typical foundry environment. A program has been developed that can take a variety of casting conditions normally prevalent in foundry practice. The output from the program that runs iteratively gives typical freezing time based on specific inputs. The mathematical formulation for a general situation is given in the following sections. The casting conditions along with the assumptions made while preparing the code are clearly stated as and when necessary. Variable temperature dependant properties like thermal conductivity, specific heat and density are appropriately taken into consideration. The program can be run for various input conditions. Change of these input conditions can be made easily through modifying the input data file. The numerical code automatically opens a file and the data generated will be stored in it, when the program terminates.

\section{Mathematical Formulation}

The governing equation for heat conduction in the radial direction in cylindrical polar coordinates is:

$$
\rho \mathrm{C}_{\mathrm{p}} \frac{\partial T}{\partial t}=\frac{1}{\mathrm{r}} \frac{\partial}{\partial r}\left(\lambda r \frac{\partial T}{\partial r}\right)
$$

This equation can be applied to the mould material. In the effective specific heat methods, the same equation is applied to the liquid and solid parts of the metal also with the appropriate values of the density, specific heat and thermal conductivity, with the solid and liquid parts distinguished based on the temperature. In the mushy zone of an alloy, between the solidus and liquids temperatures, the density, specific heat and thermal conductivity are approximated as follows:

$\rho=\frac{\rho s+\rho l}{2} ; \quad \mathrm{C}_{\mathrm{p}}=\frac{\Delta h_{s l}}{2 \Delta T}+\frac{C_{p s}+C_{p l}}{2} ; \rho=\frac{\lambda_{s}+\lambda_{l}}{2}$

where $\rho h_{s l}$ is the latent heat of solidification and $\rho t$ is onehalf of the mushy zone temperature width. For pure metal solidification, $\rho \mathrm{T}$ is prescribed to be a very small quantifies, say $0.5^{\circ} \mathrm{C}$.

At the linear surface of the metal at $r=R_{3}$, the heat loss to the rotating mass of air will be very small and hence can be neglected. Accordingly, the boundary condition is $\partial \mathrm{T} / \partial \mathrm{r}=0$ at $\mathrm{r}=\mathrm{R}_{3}$.

At the outer surface of the mould, the boundary conditions is $-\rho_{\mathrm{m}} \partial \mathrm{T} / \partial \mathrm{r}=\rho\left(\mathrm{T}-\mathrm{T}_{\mathrm{amb}}\right)$, where $\mathrm{T}_{\mathrm{amb}}$ is the ambient air temperature assumed here to be $35^{\circ} \mathrm{C}$.

The heat transfer coefficient $\rho$ is the sum of a mixed convection part $\rho_{\mathrm{mc}}$ and a radiation part $\rho_{\mathrm{r}}$.

The quantity $\rho_{\mathrm{mc}}$ is calculated using the Dropkin-Carmi relation $\mathrm{Nu}=00.19\left(\mathrm{Re}^{2}+\mathrm{Gr}\right){ }^{0.35}$. In this equation, the Reynolds number $R e$ is $D_{4}^{2} \rho / \rho_{\text {air }}$ where $D_{4}=2 R_{4}$ is the mould outer diameter, $\rho=(2 \rho / \mathrm{N}) / 60$ is the angular speed of casting and $\rho_{\text {air }}$ is the kinematic viscosity of air. The Nusselt number is defined as $\rho_{\mathrm{mc}} \mathrm{D}_{4} / \rho_{\text {air }}$. The Grashoff number is defined as $\mathrm{Gr}=\mathrm{g} \rho_{\text {air }}\left(\mathrm{T}_{\mathrm{m}, \mathrm{o}}-\mathrm{T}_{\mathrm{amb}}\right) \mathrm{D}_{4}{ }^{3} / \rho^{2}$ air. The properties are to be calculated at the mean temperature between $T_{m, o}$ and $T_{a m b}$. Thus, they are to be calculated often as $T_{m, o}$ will be changing. The quantity $\rho_{\mathrm{r}}$ is given by $\rho \rho\left(T_{m, o}+273.15\right)^{4}-\left(T_{s s}+273.15\right)^{4} /\left(T_{m, o}-T_{s s}\right)$, where $T_{s s}$ is the temperature of the surrounding surfaces in ${ }^{\circ} \mathrm{C}$. However, $T_{s s}$ is assumed to be the same as $T_{a m b}$ for simplicity. The emissivity $\rho$ of the mould outer surface is taken as 0.8. In the range of speeds 900-1440 rpm, the Reynolds number Re will be typically 70000-112000 and the Grashoff number $\mathrm{Gr}$ will be $2.5 \times 10^{7}$. The mixed convection heat transfer coefficient will be typically 70 $\mathrm{W} /\left(\mathrm{m}^{2} .{ }^{\circ} \mathrm{C}\right)$, the radiation heat transfer coefficient will be $40 \mathrm{~W} /\left(\mathrm{m}^{2} . \mathrm{C}\right)$ and the total heat transfer coefficient will be about $100 \mathrm{~W} /\left(\mathrm{m}^{2} . \mathrm{C}\right)$. Note that radiation contributes to about $35 \%$ of the total heat transfer coefficient. Hence, radiation is not negligible.

At the interface between the metal and mould the heat flux continuity, namely, $-\rho \partial \mathrm{T}_{\mathrm{s}} / \partial \mathrm{r}=-\rho_{\mathrm{m}} \partial \mathrm{T}_{\mathrm{m}} / \partial \mathrm{r}$, is applied, where the subscript $\mathrm{m}$ refers to mould and $\mathrm{s}$ refers to solid metal.

\section{Numerical Formulation}

The governing equation is discretised to yield:

$$
\begin{aligned}
& \rho_{i}^{n+1, m} C_{p, i}^{n+1, m} \frac{T_{i}^{n+1, m+1}-T_{i}^{N}}{\Delta l} \\
& \rho_{\frac{2}{r_{i}\left(\Delta r_{i-1}+\Delta r_{i}\right)}}\left[\lambda_{i+1 / 2}^{n+1, m} r_{i+1 / 2} \frac{T_{i+1}^{n+1, m+1}-T_{i}^{n+1, m+1}}{\Delta r_{i}}-\lambda_{i+1 / 2}^{n+1, m} r_{i-1 / 2} \frac{T_{i}^{n+1, m+1}-T_{i-1}^{n+1, m+1}}{\Delta r_{i-1}}\right]
\end{aligned}
$$

The above discretised equation can be written as:

$\mathrm{A}_{\mathrm{i}} T_{i-1}^{n+1, m+1}+\mathrm{B}_{\mathrm{i}} T_{i}^{n+1, m+1}+\mathrm{C}_{\mathrm{i}} T_{i+1}^{n+1, m+1}=\mathrm{D}_{\mathrm{i}}$

Where for $\mathrm{i}=2$ to il (last grid point):

$A_{i}=-q \cdot p_{1} ; B_{i}=1+q\left(p_{1}+p_{2}\right) ; C_{i}=-q \cdot p_{2} ; D_{i}=T_{i}^{n}$;

$\mathrm{q}=\frac{\Delta l}{0.5 \rho_{i}^{n+1, m} C_{p, i}^{n+1, m} r_{i}\left(\Delta r_{i-1}+\Delta r_{i}\right)}$; 
$\mathrm{p}_{1}=\frac{0.5\left(\lambda_{i-1}^{n+1, m}+\lambda_{i}^{n+1, m}\right) \cdot 0.5\left(r_{i-1}+r_{i}\right)}{\Delta r_{i-1}}$
$\mathrm{p}_{2}=\frac{0.5\left(\lambda_{i}^{n+1, m}+\lambda_{i+1}^{n+1, m}\right) \cdot 0.5\left(r_{r}+r_{+1 i}\right)}{\Delta r_{i}}$

At $\mathrm{I}=1$, i.e., the metal inner radius:

$\mathrm{A}_{\mathrm{i}}=0 ; \mathrm{B}_{\mathrm{i}}=1.0 ; \mathrm{C}_{\mathrm{i}}=-1.0$.

At $\mathrm{i}=$ ii , i.e., the metal-mould interface radius;

$\left.\mathrm{A}_{\mathrm{i}}=-\rho_{\mathrm{s}}, \rho \mathrm{r}_{\mathrm{ii}}\right\}$;

$B_{\mathrm{i}}=\rho_{\mathrm{s}}, \rho \mathrm{r}_{\mathrm{iij}}+\rho_{\mathrm{m}} \cdot \rho \mathrm{r}_{\mathrm{iij}-1}$

$\mathrm{C}_{\mathrm{i}}=\rho_{\mathrm{m}} \cdot \rho_{\mathrm{iij}-1}$;

$\mathrm{D}_{\mathrm{i}}=0$

At I $=$ il, i.e., the mould outer interface radius:

$\mathrm{A}_{\mathrm{i}}=-1.0$

$\mathrm{B}_{\mathrm{i}}=\left(1+\frac{\alpha \cdot \Delta r_{i-1}}{\lambda_{m}}\right)$

$\mathrm{C}_{\mathrm{i}}=0$

$\mathrm{D}_{\mathrm{i}}=\frac{\alpha \cdot \Delta r_{i-1}}{\lambda_{m}} \cdot \mathrm{T}_{\mathrm{amb}}$.

The quantity $\rho r_{i}$ is defined as $r_{i+1}-r_{i}$. Here $n+1$ is the new time step and $m+1$ is the new iteration at the same time step. Sufficient number of iterations (ten) are performed at every time step for proper evaluation of the properties and non-linear boundary condition involving radiation and mixed convection. At every iteration of a time step the solution is obtained using the tridiagonal matrix algorithm. The initial temperature of the mould is assumed to be $35^{\circ} \mathrm{C}$ and the initial temperature of the melt is as prescribed. The solidification time is the time when the inner surface temperature of metal falls just below the solidus temperature.

\section{Results and Discussion}

A suitable mathematical model for a Horizontal Centrifugal Casting of 4450 (A1-6.5-7.5\% Si) alloy has been developed. A detailed computer programme is written in FORTRAN 77 in cylindrical polar coordinates.

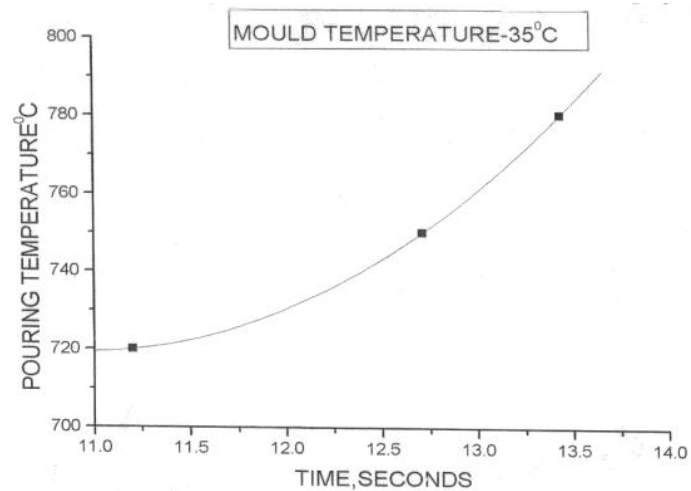

Fig. 3 shows pouring temperature Vs Time $(\mathrm{Sec})$ at $35^{\circ} \mathrm{C}$ mould temperature

A number of numerical experiments were conducted using the developed code in a wide range of parameters and for three pouring temperatures and two different speeds. The pouring temperatures were taken as $720^{\circ} \mathrm{C}, 750^{\circ} \mathrm{C}$ and $780^{\circ} \mathrm{C}$ respectively. The two speeds at which the molten metal was poured are 900 and $1440 \mathrm{rpm}$. In the present study, cylindrical shell Horizontal Centrifugal Casting mould having an internal diameter of $50.88 \mathrm{~mm}$ and a wall thickness $36 \mathrm{~mm}$ is considered. Parameters chosen in a wide range cover the large variations in thermal properties of mould material and cast material the convective heat transfer coefficient and radiative heat transfer coefficient. The results of the numerical solution were presented in the preceding sections. A graphical representation of variation in the freezing time as a function of pouring temperature is shown in Fig.3, Fig.4, and Fig5.

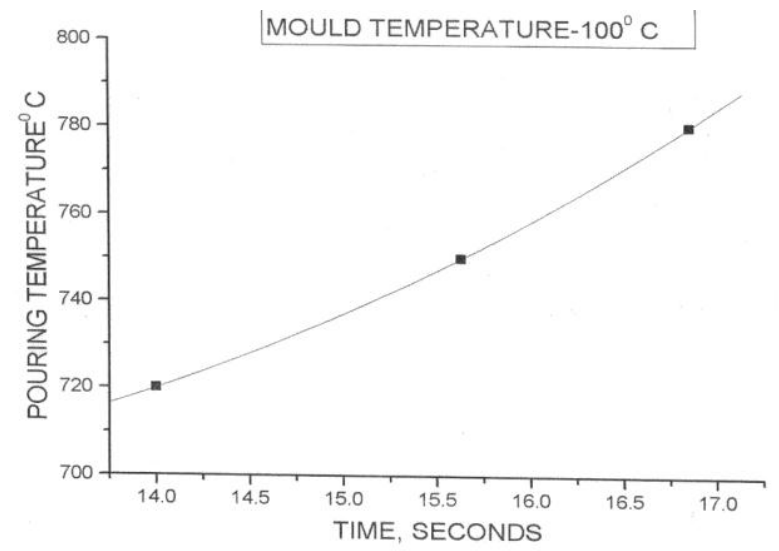

Fig. 4. Shows pouring temperature Vs Time (Sec) at $100^{\circ} \mathrm{C}$ mould temperature

Normally centrifugal casting process is a continuous process wherein the mould temperature will not be at room temperature. It is expected that the mould temperature will be around $100^{\circ} \mathrm{C}$ which would increase the freezing time considerably. The solidification time typically is of the order of 15 seconds. When the mould reaches the working temperature.

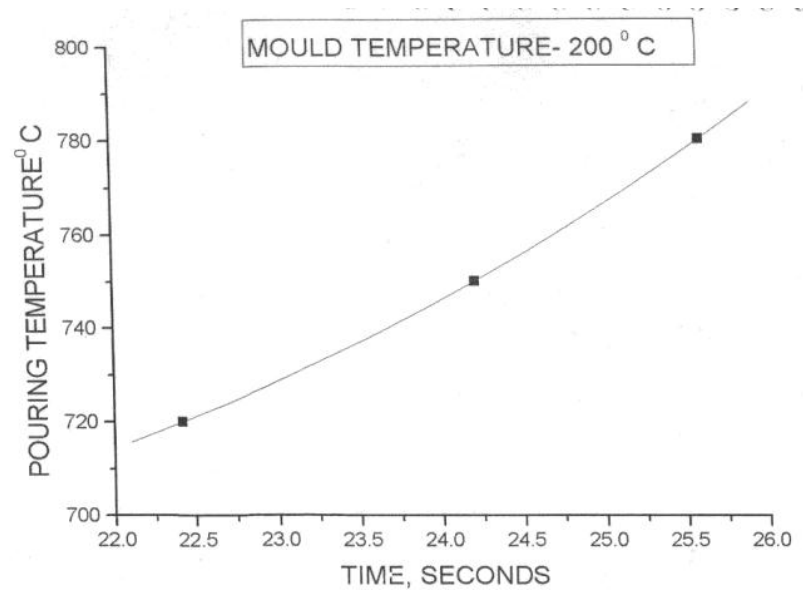

Fig. 5 Shows pouring temperature Vs Time $(\mathrm{Sec})$ at $200^{\circ}$ $\mathrm{C}$ mould temperature

The time temperature variation in the mould wall and solidification time for horizontal centrifugal casting of $4450 \mathrm{Al}-7 \%$ Si Alloy were arrived at

- When the pouring temperature is at $720^{\circ} \mathrm{C}$ and the mould temperature is $35^{\circ} \mathrm{C}$ the freezing time is less i.e., at the solidus point. Whereas when the pouring temperature is increased to $780^{\circ} \mathrm{C}$ and the mould 
temperature is $35^{\circ} \mathrm{C}$ there is a obvious rise in the solidification time.

- When the mould temperature is at $35^{\circ} \mathrm{C}$ and the pouring temperature is $720^{\circ} \mathrm{C}$. the freezing time is 11.2 seconds at the solidus point. When the mould temperature is increased to $100^{\circ} \mathrm{C}$ while the pouring temperature is maintained at $720^{\circ} \mathrm{C}$ the freezing time increases to 15 seconds. Similarly when the mould temperature reaches $200^{\circ} \mathrm{C}$ for the pouring temperature of $720^{\circ} \mathrm{C}$ the freezing time further increases to 22.42 seconds.

- It has been observed that there is no rise in the solidification time when the rotation speed of the mould increases from $900 \mathrm{rpm}$ to $1440 \mathrm{rpm}$.

- There is a good agreement between the numerical results and the experimentally observed values.

- The rate of heat extracted at any instant of time will be less in thin walled moulds than in thick walled moulds due to the heat capacity associated with the mould materials.

- The freezing time is found to be independent of the rotational speed of the Mould in the range considered in the present investigation.

- As the rotational speed of the mould increases the convective heat transfer coefficient on the External surface also increases, because the Reynolds number increases. As a consequence the cooling rates increases as a function of Reynolds number. This results in the reduced solidification time of the Molten Metal. The speed of the Mould as such will not have a great influence on the freezing time for the reason that the density of the molten metal does not change considerably. There may be a perceivable change in the freezing time at very high speeds such that the centrifugal force causes a change in the density of the molten metal. As these speeds are beyond the scope of present investigations the data is insufficient to make a firm conclusion in this regard.

\section{Conclusions}

Heat transfer analysis is carried out through FORTRAN programme indicated that

1. With increase in the preheat temperature of the die cast mould the thickness of the solidification layer is get reduced while preheating is desirable to remove the hot cracking tendency of the alloy. The same is not desirable from the mechanical strength point of view.

2. Freezing time of molten metal in centrifugal casting is a strong function of mould temperature as well as the pouring temperature.

3. The freezing time is completely independent of the rotational speed of the mould in the range considered in the present investigation.

4. The predictive capabilities of the numerical code developed for the present work is established by comparing numerical results with that of experimental values.

\section{References}

H.Md. Roshan, (1947), Analytical Solution to the Heat Transfer in Mould walls during solidification of metals, AFS Cast Metals Research Journal, pp 39-47.

Bahadori M.N (1971), Control of Solidification Rate by Application of Heat Pipe Principle, Cast Metals Research Journal, pp.62-66.

E Kaschnitz (2012) Numerical simulation of centrifugal casting of pipes IOP Conf. Series: Materials Science and Engineering33012031.

Jezierski J(1970), Analysis of the State of Thermal Stress in Moulds during Centrifugal Casting, AFS Cast Metals Research Journal, pp.75-79.1

LazardisA (1970), Thermal Analysis of Centrifugal Casting Moulds, AFS Cast Metals Research Journal, pp.153-160.

Tae-Gyu Kim (1997), Time Varying Heat Transfer Coefficients between Tube Shaped Casting and Metal Mould, Pergamon, pp.3513-3525

Minosyan Ya P (1983), Mathematical Simulation of Centrifugal Casting of Pipes, Heat Transfer Soviet Research Journal, pp.134140. 